
3 Research Square
Preprints are preliminary reports that have not undergone peer review.
They should not be considered conclusive, used to inform clinical practice, or referenced by the media as validated information.

\title{
The Role of Radiotherapy Fractionation And Volume In Patients With Early Breast Cancer After Conserving Surgery: A Systematic Review And Network Meta-Analysis
}

\author{
Xian Chen \\ The Third Affiliated Hospital of Kunming Medical University: Yunnan Cancer Hospital \\ Tong-Xin Yang \\ Kunming Medical University Second Hospital \\ Yao-Xiong Xia \\ The Third Affiliated Hospital of Kunming Medical University: Yunnan Cancer Hospital \\ Qi Shen \\ The Third Affiliated Hospital of Kunming Medical University: Yunnan Cancer Hospital \\ Yu Hou \\ The Third Affiliated Hospital of Kunming Medical University: Yunnan Cancer Hospital \\ Li Wang \\ The Third Affiliated Hospital of Kunming Medical University: Yunnan Cancer Hospital \\ Lan Li \\ The Third Affiliated Hospital of Kunming Medical University: Yunnan Cancer Hospital \\ Li Chang \\ The Third Affiliated Hospital of Kunming Medical University: Yunnan Cancer Hospital \\ Wen-Hui LI ( $\square$ wenhuili2014@163.com) \\ The Third Affiliated Hospital of Kunming Medical University: Yunnan Cancer Hospital https://orcid.org/0000-0003-3019-0450
}

Research

Keywords: Hypofractionated radiotherapy, Conventional fractionated radiotherapy, Partial-breast irradiation, Breast cancer, Breast-conserving surgery

Posted Date: January 25th, 2021

DOI: https://doi.org/10.21203/rs.3.rs-152455/v1

License: @ (7) This work is licensed under a Creative Commons Attribution 4.0 International License. Read Full License 


\section{Abstract}

Background $/$ Hypofractionated whole breast irradiation (HF-WBI) can achieve the same treatment effect as conventional fractionated whole breast irradiation (CF-WBI) within limits, without increasing adverse reactions. Because of its characteristics of reducing the number of radiation therapy (RT) during the COVID19 Pandemic, it is recommended as the first choice of treatment for patients with early breast cancer after breast conserving surgery. However, the choice of RT is still under exploration. Here, we conducted a network meta-analysis to evaluate the problem comprehensively using data from new randomized trials.

Methods: We analyzed data from eligible studies for published events for ipsilateral breast tumor recurrence (IBTR), distant metastasis, total deaths, and nonbreast cancer-related deaths. Statistical analysis was performed using a fixed-effects or random-effects model in cases of low and high heterogeneity, respectively. Network meta-analysis was conducted using a node-splitting model for two-category data among three RTs based on a Bayesian approach.

Results: 16 studies with 23,418 patients were included. For IBTR, pairwise comparison showed that CF-WBI was significantly better than PBI, and HF-WBI was similar to CF-WBI. HF-WBI was superior to PBI, but the difference was not significant. However, indirect comparison of three RTs by network meta-analysis showed that HF-WBI was significantly better than $\mathrm{PBI}(\mathrm{OR}=0.67, \mathrm{CI} 95 \%$ : 0.46-0.95). Paired and network meta-analyses found no significant differences in other endpoints among three radiotherapies.

Conclusion: This meta-analysis demonstrated PBI was associated with increased IBTR compared with HF-WBI or CF-WBI in early-stage breast cancer patients.

\section{Background}

Changes in radiation therapy (RT) fractionation have long been studied in relation to various types of cancer, including breast cancer. The standard treatment for early breast cancer is breast-conserving surgery supplemented by whole-breast irradiation (WBI) and appropriate systemic therapy. However, a long course of conventional fractionated WBI (CF-WBI) for 5-6 weeks not only increases the economic burden on patients, but also affects the turnover of medical resources, thus limiting the popularity of breast-conserving surgery. Breast cancer tissue is as sensitive to fraction size as dose-limiting healthy tissues, so RT schedules can be greatly simplified by the delivery of fewer, larger fractions without compromising effectiveness or safety, and possibly improving both[1]. Moderate hypofractionated WBI (HF-WBI), defined as a daily dose of 265-330 cGy, is delivered in 13-16 fractions[2]. Four large randomized controlled trials demonstrated that HF-WBI provided equivalent local control and overall survival to CF-WBI[1-4]. The American Society for Radiation Oncology (ASTRO) guidelines in 2018 therefore broadened the HF-WBI adaptive population, with no restrictions on age, stage, or chemotherapy. A scheme of 40.0-42.5 Gy/1516 fractions was suggested[5]. National Comprehensive Cancer Network guidelines currently recommend that WBI should be given priority to HF-WBI scheme. However, HF-WBI is only used in $34.5 \%$ of patients in the United States[6], and in as few as $12.1 \%$ of patients in China[7]. The slow adoption of HF-WBI in Asia and the United States may be related to physicians' concerns about the cosmetic side effects, especially when used in conjunction with tumor-bed boost and chemotherapy, or its use in patients with different breast sizes, or the absence of validation outside Canada and the United Kingdom[6]. Several randomized controlled trials are currently comparing the effects of HF-WBI and CF-WBI in terms of local tumor control, breast appearance (cosmesis), late toxicity, overall survival, and patient satisfaction[8-13].

On the other hand, analysis of local recurrence in patients treated for early breast cancer indicates that most recurrence occurs at the initial tumor location[1417]. This suggests that irradiation of the tumor bed alone may be equally effective to WBI, with fewer side effects. Multiple randomized trials using different techniques have provided conflicting results for tumor control, toxicity, and survival, mainly due to the heterogeneity of the trials and small sample sizes[1826]. Based on these trials, ASTRO and the German Association of Radiology Oncology produced their accelerated PBI (APBI) criteria for patient selection and recommendations for irradiation methods[27,28]. Over recent decades, increasing attention has been paid to the dose-dependent effects of WBI on major coronary artery events[29,30] and secondary malignancies, including lung cancer[30]. PBI is presumed to reduce the occurrence of these late adverse events by reducing the radiation dose to the corresponding organs.

Several new trials have published results, while several large trials have updated longer follow-up results. The interventions to be compared are more than 2 (in this case, 3 ) and not all articles report all three single comparisons (PBI vs. CF-WBI, PBI vs. HF-WBI, and CF-WBI vs. HF-WBI), so network meta-analysis is done. We conducted a comprehensive assessment of three RT modalities (PBI, HF-WBI, and CF-WBI) based on the results of recently published trials and update long-term follow-up trials data to evaluate and compare the effectiveness of PBI, HF-WBI, and HF-WBI.

\section{Methods}

This meta-analysis was carried out in accordance with the Cochrane Collaboration Handbook of Interventions Systematic Reviews ${ }^{[31]}$. The study followed the PRISMA reporting guidelines[32]. This review was prospectively registered in the PROSPERO database (Registration Number CRD42020219183).

\section{Search strategy}

We searched the following databases on 10 october 2020: Cochrane Central Register of Controlled Trials (2019, via the Cochrane Library), Central Register of Controlled Trials (CENTRAL, 2017 issue 7, via Wiley), MEDLINE 1966 to 25 July 2019, via Pubmed), and Embase (1988 to July 2019 , via Elsevier). The electronic search was conducted with no language, publication year, or publication status restrictions. The selected search terms included (((early breast neoplasm) OR (early breast tumor) OR (early human mammary carcinoma) OR (early human mammary neoplasm) OR (early breast cancer)) AND ((wholebreast irradiation) OR (WBI) OR (APBI) OR (accelerated partial breast irradiation) OR (accelerated partial irradiation) OR (PBI) OR (partial breast irradiation) OR (interstitial brachytherapy) OR (multicatheter interstitial brachytherapy) OR (MIB) OR (balloon catheter brachytherapy) OR (intracavitary brachytherapy) OR (intraoperative radiotherapy) OR (IORT) OR (conformal external beam) OR (three-dimensional conformal radiotherapy) OR (3D-CRT) OR (intensity-modulated 
radiotherapy) OR (IMRT) OR (hypofraction irradiation) OR (hypofractionated radiotherapy) OR (hypofraction radiotherapy))) AND ((segmental mastectomy) OR (partial mastectomy) OR (limited resection mastectomy) OR (lumpectomy) OR (local excision mastectomy) OR (breast-conserving surgery)).

\section{Study inclusion/exclusion criteria}

After the literature search, we included CF-WBI, HF-WBI, and PBI as the interventional postoperative RT arms in patients with early breast cancer. We pooled the results of different PBI techniques, such as external-beam radiation, intraoperative RT using electrons or photons, as well brachytherapy, including single- or multi-catheter-based approaches. The patients had to have undergone breast-conserving surgery and to have histologically confirmed primary breast cancer, either invasive or in situ breast cancer. The boost was assessed by the physicians in each study according to the risk of recurrence. Adjuvant systemic treatments were allowed. The included trials were published after 1 January 2000 , to include comparable modern technologies. We excluded trials that compared different HF-WBI radiotherapy. The FAST[8] and FAST FORWARD[33] studies shortened 3-5 weeks of treatment to just 1 week, to explore the efficacy and safety of single-week ultra-hypofractionation. We included the FAST study but excluded the FAST FORWARD study in our analysis, because of the lack of a control arm. The TARGIT group recently updated the long-term results for the post-pathology or delayed-treatment subgroup, and we therefore split the trial into an original pre-pathology group and a delayed group, to allow the most appropriate estimation of the desired comparison ${ }^{22,23}$. The START study included two studies, Start A and Start B. Data for the longest follow-up period were published jointly in 2013. According to the authors' intention, we obtained data for the two studies from the joint paper ${ }^{9}$.

\section{Data extraction}

The data were extracted by two independent reviewers (Chen and Yang). A third reviewer resolved any disagreements (Chang). 16 studies with 23,418 patients were included. The outcome indicators in this study were the number of ipsilateral breast tumor recurrences (IBTR), distant metastases, total deaths, and nonbreast cancer-related deaths recorded at the endpoints in each included study. IBTR included tumor-bed relapse and new tumors in the ipsilateral breast. Distant metastasis of breast cancer was defined as metastases at all sites outside the quadrant where the tumor was located. Studies evaluating acute and late side effects and cosmetic effects used different evaluation criteria. It was therefore not possible to classify these indicators, which will be examined in another systematic review.

\section{Risk of bias assessment}

Two review authors (Chen and Yang) independently evaluated all relevant clinical studies for methodological quality. Each review author performed this assessment using the Cochrane Collaboration's Risk of Bias tool, which included quality of random allocation concealment, description of dropout and withdrawal, intention-to-treat analysis, and blinding procedures for treatment and outcome assessments[34]. A third reviewer resolved any disagreements by discussion (Chang).

\section{Statistical analysis}

Statistical analysis was performed using the GeMTC package in R (version 4.0.2). A node-splitting model[35] for two-category data among all three intervention arms based on a Bayesian approach was established. Odds ratios (OR) with 95\% confidence intervals (Cl) were calculated to determine the favored arm. Network consistency was analyzed by calculating the ratio of direct and indirect treatment effects within each comparison, with $95 \%$ Cls. If the $95 \% \mathrm{Cl}$ was $>1.00$ or $<1.00$, the difference was considered significant $(\mathrm{p}<0.05)$. $\mathrm{I}^{2}$ was used to assess the risk of bias in each model. $I^{2}<50 \%$ means that there is a low risk of bias in the model.

\section{Results}

\section{Study characteristics}

The flowchart with the process of the studies selection is detailed as shown in Figure 1. 16 studies retrieved fulfilled the inclusion criteria for this review (Table 1). A total of 23,418 patients were included, most of them with node negative, hormone receptor positive, tumor stage T1-T2 and N0 low-risk breast cancer patients. The intention-to-treat principle was respected for all analyses. Hypofractionated doses ranged from 2.7 to 6.0 Gy and total doses from 28.5 to 43.5 Gy. Tumor bed boosting and regional lymph node irradiation were not permitted in some trials, and mandated in others. Except for the natural defect blinding, all studies were considered as high quality and low risk of bias. Although there were some differences in patient selection criteria, adjuvant therapy regimens and the RT technique included in the trial, local control rates were similar in the CF-WBI group, suggesting that it may be a way to control differences in selection[1,8-13,18-21,36].

\section{Breast Cancer Ipsilateral Breast tumor recurrence}

Sixteen studies reported IBTR, including seven studies for HF-WBI vs CF-WBI, seven studies for PBI vs CF-WBI, and two studies for PBI vs HF-WBI. The network meta-analysis (Figure 2) showed that CF-WBI was significantly better than PBI (OR=1.5; CI95\%: 1.2-2.0; $p<0.05)$ and $\mathrm{HF}-\mathrm{WBI}$ was also significantly better than $\mathrm{PBI}(\mathrm{OR}=1.5 ; \mathrm{CI} 95 \%: 1.1-2.1 ; p<0.05)$. There was no significant difference (OR=0.97; Cl95\%: 0.72-1.3; $p>0.05)$ between the HF-WBI and $\mathrm{CF}-\mathrm{WBI}$ groups. Among them, only two RCTs compared IBTR between the HF-WBI and PBI groups. There was no significant difference according to pairwise meta-analysis (OR=1.1; 
Cl95\%: 0.58-2.0; $p>0.05)$, but network meta-analysis using indirect comparison of the three intervention arms showed that HF-WBI was significantly better than PBI (Figure. 2). There were no detectable heterogeneity between all trials in the network meta-analysis $\left(I^{2}<50\right)$.

\section{Distant metastasis}

Thirteen studies reported distant metastasis, including five studies for HF-WBI vs CF-WBI, six studies for PBI vs CF-WBI, and two studies for HF-WBI vs PBI. The network meta-analysis (Figure 3) showed that there was no significant difference in the HF-WBI vs CF-WBI comparison (OR=1.1; CI95\%: $0.81-1.4$; $p>0.05)$, the $\mathrm{PBI}$ vs CF-WBI comparison (OR=1.0; CI95\%: 0.76-1.4; $\mathrm{p}>0.05)$, and the $\mathrm{PBI}$ vs HF-WBI comparison (OR=0.98; $\mathrm{Cl} 95 \%$ : 0.66-1.4; $p>0.05$ ). There was detectable heterogeneity between HF-WBI and CF-WBI groups $\left(\mathrm{I}^{2}=66.7 \%\right)$. But, even with moderate heterogeneity, this part of comparison yielded interpretable results, with no significant difference between CF-WBI and HF-WBI in distant metastasis.

\section{Total deaths}

Thirteen studies reported total deaths, including five studies for HF-WBI vs CF-WBI, six studies for PBI vs CF-WBI, and two studies for HF-WBI vs PBI. Figure 4 shows the network meta-analysis of total deaths among three RTs, which was not statistically different between each other. There were no detectable heterogeneity between the trials $\left(I^{2}=0\right)$.

\section{Non-breast cancer deaths}

Eleven studies reported non-breast cancer-related deaths, including four studies for HF-WBI vs CF-WBI, six studies for PBI vs CF-WBI, and one study for HF-WBI vs PBI. Figure 5 shows the network meta-analysis of non-breast cancer deaths among three RTs, which was not statistically different between each other. There were no detectable heterogeneity between the trials $\left(I^{2}<50 \%\right)$.

\section{Conclusions}

In summary, this meta-analysis demonstrated PBI was associated with increased IBTR compared with HF-WBI or CF-WBI in early-stage breast cancer patients, and further research is still needed to compare the adverse effects and cosmesis of three distinct RT approach. There were no statistically difference among the RTs in terms of distant metastases, total deaths, and non-breast cancer mortality.

\section{Abbreviations}

CF-WBI: Conventional Fractionated Whole Breast Irradiation

HF-WBI: Hypofractionated Whole Breast Irradiation

PBI: Partial Breast Irradiation

IBTR: Ipsilateral Breast Tumor Recurrence

LR: Local relapse

LRR: Local-regional relapse

RT: Radiation therapy

APBI: Accelerated partial breast irradiation

\section{Declarations}

\section{Author Contributions:}

Wen-Hui Li: Conceptualization. Xian Chen: Methodology, Software. Tong-xin Yang: Data curation, Writing, Original draft preparation. Yao-Xiong Xia: Visualization, Investigation. Qi Shen: Supervision. Yu Hou, Li Wang, Lan Li: Software, Validation. Li Chang: Writing, Reviewing and Editing. All authors have read and agreed to the published version of the manuscript.

Funding: This research was funded by National Key Research and Development Program of China (No.2018YFC1311400/2018YFC1311402), Ten-thousand Talents Program of Yunnan Province (Yunling scholar, Youth talent), Yunnan Provincial Training Funds for Middle-Young Academic and Technical Leader candidate (202005AC160025), Yunnan Provincial Training Funds for High-level Health Technical Personnel (No.L-2018001).

Acknowledgments: Xian Chen, Tong-Xin Yang and Yao-Xiong Xia contributed equally to this work.

Conflicts of Interest: The authors declare no conflict of interest. The funders had no role in the design of the study; in the collection, analyses, or interpretation of data; in the writing of the manuscript, or in the decision to publish the results.

Ethics approval and consent to participate 『Not applicable

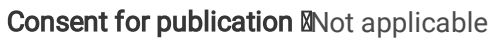


Availability of data and material बThe datasets used and/or analyzed during the current study are available from the corresponding author on reasonable request.

\section{References}

1. Owen JR, Ashton A, Bliss JM, et al. Effect of radiotherapy fraction size on tumour control in patients with early-stage breast cancer after local tumour excision: long-term results of a randomised trial. Lancet Oncol. 2006;7(6):467-471.

2. Whelan T, MacKenzie R, Julian J, et al. Randomized trial of breast irradiation schedules after lumpectomy for women with lymph node-negative breast cancer. J Natl Cancer Inst. 2002;94(15):1143-1150.

3. Group ST, Bentzen SM, Agrawal RK, et al. The UK Standardisation of Breast Radiotherapy (START) Trial B of radiotherapy hypofractionation for treatment of early breast cancer: a randomised trial. Lancet. 2008;371(9618):1098-1107.

4. Group ST, Bentzen SM, Agrawal RK, et al. The UK Standardisation of Breast Radiotherapy (START) Trial A of radiotherapy hypofractionation for treatment of early breast cancer: a randomised trial. Lancet Oncol. 2008;9(4):331-341.

5. Smith BD, Bellon JR, Blitzblau R, et al. Radiation therapy for the whole breast: Executive summary of an American Society for Radiation Oncology (ASTRO) evidence-based guideline. Pract Radiat Oncol. 2018;8(3):145-152.

6. Bekelman JE, Sylwestrzak G, Barron J, et al. Uptake and costs of hypofractionated vs conventional whole breast irradiation after breast conserving surgery in the United States, 2008-2013. JAMA. 2014;312(23):2542-2550.

7. Chen SY TY, Song YW, et al. Prognosis and risk factors of 1791 patients with breast cancer treated with breast-conserving surgery based on real-world data. Zhonghua Zhong Liu Za Zhi 40:619-625, 2018. 2018.

8. Brunt AM, Haviland JS, Sydenham M, et al. Ten-Year Results of FAST: A Randomized Controlled Trial of 5-Fraction Whole-Breast Radiotherapy for Early Breast Cancer. J Clin Oncol. 2020:JC01902750.

9. Haviland JS, Owen JR, Dewar JA, et al. The UK Standardisation of Breast Radiotherapy (START) trials of radiotherapy hypofractionation for treatment of early breast cancer: 10-year follow-up results of two randomised controlled trials. Lancet Oncol. 2013;14(11):1086-1094.

10. Hou HL, Song YC, Li RY, et al. Similar Outcomes of Standard Radiotherapy and Hypofractionated Radiotherapy Following Breast-Conserving Surgery. Med Sci Monit. 2015;21:2251-2256.

11. Spooner D, Stocken DD, Jordan S, et al. A randomised controlled trial to evaluate both the role and the optimal fractionation of radiotherapy in the conservative management of early breast cancer. Clin Oncol (R Coll Radiol). 2012;24(10):697-706.

12. Wang SL, Fang H, Hu C, et al. Hypofractionated Versus Conventional Fractionated Radiotherapy After Breast-Conserving Surgery in the Modern Treatment Era: A Multicenter, Randomized Controlled Trial From China. J Clin Oncol. 2020:JCO2001024.

13. Whelan TJ, Pignol JP, Levine MN, et al. Long-term results of hypofractionated radiation therapy for breast cancer. N Engl J Med. 2010;362(6):513-520.

14. Smith TE, Lee D, Turner BC, Carter D, Haffty BG. True recurrence vs. new primary ipsilateral breast tumor relapse: an analysis of clinical and pathologic differences and their implications in natural history, prognoses, and therapeutic management. Int J Radiat Oncol Biol Phys. 2000;48(5):1281-1289.

15. Gujral DM, Sumo G, Owen JR, et al. Ipsilateral breast tumor relapse: local recurrence versus new primary tumor and the effect of whole-breast radiotherapy on the rate of new primaries. Int J Radiat Oncol Biol Phys. 2011;79(1):19-25.

16. Vaidya JS, Vyas JJ, Chinoy RF, Merchant N, Sharma OP, Mittra I. Multicentricity of breast cancer: whole-organ analysis and clinical implications. Br J Cancer. 1996;74(5):820-824.

17. Kaiser J, Reitsamer R, Kopp P, et al. Intraoperative Electron Radiotherapy (IOERT) in the Treatment of Primary Breast Cancer. Breast Care (Basel). 2018;13(3):162-167.

18. Livi L, Meattini I, Marrazzo L, et al. Accelerated partial breast irradiation using intensity-modulated radiotherapy versus whole breast irradiation: 5-year survival analysis of a phase 3 randomised controlled trial. Eur J Cancer. 2015;51(4):451-463.

19. Meattini I, Marrazzo L, Saieva C, et al. Accelerated Partial-Breast Irradiation Compared With Whole-Breast Irradiation for Early Breast Cancer: Long-Term Results of the Randomized Phase III APBI-IMRT-Florence Trial. J Clin Oncol. 2020:JC02000650.

20. Polgar C, Fodor J, Major T, Sulyok Z, Kasler M. Breast-conserving therapy with partial or whole breast irradiation: ten-year results of the Budapest randomized trial. Radiother Oncol. 2013;108(2):197-202.

21. Strnad V, Ott OJ, Hildebrandt G, et al. 5-year results of accelerated partial breast irradiation using sole interstitial multicatheter brachytherapy versus whole-breast irradiation with boost after breast-conserving surgery for low-risk invasive and in-situ carcinoma of the female breast: a randomised, phase 3, non-inferiority trial. Lancet. 2016;387(10015):229-238.

22. Vaidya JS, Bulsara M, Baum M, et al. Long term survival and local control outcomes from single dose targeted intraoperative radiotherapy during lumpectomy (TARGIT-IORT) for early breast cancer: TARGIT-A randomised clinical trial. BMJ. 2020;370:m2836.

23. Vaidya JS, Bulsara M, Saunders C, et al. Effect of Delayed Targeted Intraoperative Radiotherapy vs Whole-Breast Radiotherapy on Local Recurrence and Survival: Long-term Results From the TARGIT-A Randomized Clinical Trial in Early Breast Cancer. JAMA Oncol. 2020;6(7):e200249.

24. Veronesi U, Orecchia R, Maisonneuve P, et al. Intraoperative radiotherapy versus external radiotherapy for early breast cancer (ELIOT): a randomised controlled equivalence trial. Lancet Oncol. 2013;14(13):1269-1277.

25. Vicini FA, Cecchini RS, White JR, et al. Long-term primary results of accelerated partial breast irradiation after breast-conserving surgery for early-stage breast cancer: a randomised, phase 3, equivalence trial. Lancet. 2019;394(10215):2155-2164. 
26. Whelan TJ, Julian JA, Berrang TS, et al. External beam accelerated partial breast irradiation versus whole breast irradiation after breast conserving surgery in women with ductal carcinoma in situ and node-negative breast cancer (RAPID): a randomised controlled trial. Lancet. 2019;394(10215):2165-2172.

27. Strnad V, Krug D, Sedlmayer F, et al. DEGRO practical guideline for partial-breast irradiation. Strahlenther Onkol. 2020;196(9):749-763.

28. Correa C, Harris EE, Leonardi MC, et al. Accelerated Partial Breast Irradiation: Executive summary for the update of an ASTRO Evidence-Based Consensus Statement. Pract Radiat Oncol. 2017;7(2):73-79.

29. Darby SC, Ewertz M, McGale P, et al. Risk of ischemic heart disease in women after radiotherapy for breast cancer. N Engl J Med. 2013;368(11):987-998.

30. Taylor C, Correa C, Duane FK, et al. Estimating the Risks of Breast Cancer Radiotherapy: Evidence From Modern Radiation Doses to the Lungs and Heart and From Previous Randomized Trials. J Clin Oncol. 2017;35(15):1641-1649.

31. Higgins JPT TJ, Chandler J, Cumpston M, Li T, Page MJ, Welch VA editors. Cochrane Handbook for Systematic Reviews of Interventions version 6.0 (updated July 2019). 2019.

32. Liberati A, Altman DG, Tetzlaff J, et al. The PRISMA statement for reporting systematic reviews and meta-analyses of studies that evaluate healthcare interventions: explanation and elaboration. BMJ. 2009;339:b2700.

33. Murray Brunt A, Haviland JS, Wheatley DA, et al. Hypofractionated breast radiotherapy for 1 week versus 3 weeks (FAST-Forward): 5-year efficacy and late normal tissue effects results from a multicentre, non-inferiority, randomised, phase 3 trial. Lancet. 2020;395(10237):1613-1626.

34. Cumpston M, Li T, Page MJ, et al. Updated guidance for trusted systematic reviews: a new edition of the Cochrane Handbook for Systematic Reviews of Interventions. Cochrane Database Syst Rev. 2019;10:Ed000142.

35. van Valkenhoef G, Dias S, Ades AE, Welton NJ. Automated generation of node-splitting models for assessment of inconsistency in network meta-analysis. Res Synth Methods. 2016;7(1):80-93.

36. !!! INVALID CITATION !!! .

37. Haussmann J, Budach W, Corradini S, et al. No Difference in Overall Survival and Non-Breast Cancer Deaths after Partial Breast Radiotherapy Compared to Whole Breast Radiotherapy-A Meta-Analysis of Randomized Trials. Cancers (Basel). 2020;12(8).

38. Valle LF, Agarwal S, Bickel KE, Herchek HA, Nalepinski DC, Kapadia NS. Hypofractionated whole breast radiotherapy in breast conservation for early-stage breast cancer: a systematic review and meta-analysis of randomized trials. Breast Cancer Res Treat. 2017;162(3):409-417.

39. Andrade TRM, Fonseca MCM, Segreto HRC, Segreto RA, Martella E, Nazario ACP. Meta-analysis of long-term efficacy and safety of hypofractionated radiotherapy in the treatment of early breast cancer. Breast. 2019;48:24-31.

40. Yarnold J, Ashton A, Bliss J, et al. Fractionation sensitivity and dose response of late adverse effects in the breast after radiotherapy for early breast cancer: long-term results of a randomised trial. Radiother Oncol. 2005;75(1):9-17.

41. Marta GN, Macedo CR, Carvalho Hde A, Hanna SA, da Silva JL, Riera R. Accelerated partial irradiation for breast cancer: systematic review and metaanalysis of 8653 women in eight randomized trials. Radiother Oncol. 2015;114(1):42-49.

42. Vaidya JS, Bulsara M, Wenz F, et al. Reduced Mortality With Partial-Breast Irradiation for Early Breast Cancer: A Meta-Analysis of Randomized Trials. Int J Radiat Oncol Biol Phys. 2016;96(2):259-265.

43. Marta GN, Barrett J, Porfirio GJM, et al. Effectiveness of different accelerated partial breast irradiation techniques for the treatment of breast cancer patients: Systematic review using indirect comparisons of randomized clinical trials. Rep Pract Oncol Radiother. 2019;24(2):165-174.

44. Coles CE, Griffin CL, Kirby AM, et al. Partial-breast radiotherapy after breast conservation surgery for patients with early breast cancer (UK IMPORT LOW trial): 5-year results from a multicentre, randomised, controlled, phase 3, non-inferiority trial. Lancet. 2017;390(10099):1048-1060.

45. Coles CE, Aristei C, Bliss J, et al. International Guidelines on Radiation Therapy for Breast Cancer During the COVID-19 Pandemic. Clin Oncol (R Coll Radiol). 2020;32(5):279-281.

46. Marta GN, Poortmans P. Moderately hypofractionated breast radiation therapy: is more evidence needed? Lancet Oncol. 2019;20(5):e226.

47. Lansu JT, Essers M, Voogd AC, et al. The influence of simultaneous integrated boost, hypofractionation and oncoplastic surgery on cosmetic outcome and PROMs after breast conserving therapy. Eur J Surg Oncol. 2015;41(10):1411-1416.

\section{Tables}




\begin{tabular}{|c|c|c|c|c|c|c|c|c|c|c|}
\hline Study & Synonym & $\begin{array}{l}\text { Study } \\
\text { Period }\end{array}$ & $\begin{array}{l}\text { Maximum } \\
\text { Follow-up, } \\
\text { year }\end{array}$ & No. & $\begin{array}{l}\text { Medean } \\
\text { Age }\end{array}$ & $\begin{array}{l}\text { Primary } \\
\text { Endpoints }\end{array}$ & population & $\begin{array}{l}\text { PBI } \\
\text { Technique }\end{array}$ & PBI Dose & CF-WBI Dose \\
\hline $\begin{array}{l}\text { Vaidya } \\
2020\end{array}$ & TARGIT-A & $\begin{array}{l}03 / 2000- \\
06 / 2012\end{array}$ & 8.6 & 2298 & $\begin{array}{l}\text { Mean } \\
63\end{array}$ & IBTR & $\begin{array}{l}\text { IDC; } T<2.5 \mathrm{~cm} ; \\
\text { R0; >45 } \\
\text { y;unifocal }\end{array}$ & IORT $x$ & $20 / 20$ & $30 / 2-50 / 2$ \\
\hline $\begin{array}{l}\text { Vaidya } \\
2020\end{array}$ & $\begin{array}{l}\text { delayed } \\
\text { TARGIT-A }\end{array}$ & $\begin{array}{l}03 / 2000- \\
06 / 2012\end{array}$ & 9 & 1153 & $\begin{array}{l}\text { Mean } \\
63\end{array}$ & IBTR & $\begin{array}{l}\text { IDC;T<2.5 } \\
\text { cm; } \\
\text { R0; > }>45 \\
\text { y;unifocal }\end{array}$ & IORT $x$ & $20 / 20$ & $30 / 2-50 / 2$ \\
\hline $\begin{array}{l}\text { Meattini } \\
2020\end{array}$ & Florence & $\begin{array}{l}03 / 2005- \\
06 / 2013\end{array}$ & 10 & 520 & 62.8 & IBTR & $\begin{array}{l}\text { IBC or } \\
\text { DCIS; } \\
\text { T<2.5 cm; } \\
>40 \text { y }\end{array}$ & IMRT & $30 / 6$ & $\begin{array}{l}50 / 2+ \\
10 / 2 \text { TBB }\end{array}$ \\
\hline $\begin{array}{l}\text { Whelan } \\
2019\end{array}$ & RAPID & $\begin{array}{l}02 / 2006- \\
07 / 2011\end{array}$ & 8.6 & 2135 & 61 & IBTR & $\begin{array}{l}\text { IBC or } \\
\text { DCIS; } \\
\text { T< } \\
\text { 3cm;R0;NO; } \\
>40 \\
\text { y;unifocal }\end{array}$ & 3DCRT, IMRT & $\begin{array}{l}38.5 / 3.85 \\
\text { BID in } \\
5-8 d\end{array}$ & $\begin{array}{l}\text { (192) 50/2区 } \\
\text { (873)42.5/2.66; }\end{array}$ \\
\hline $\begin{array}{l}\text { Vicini } \\
2019\end{array}$ & $\begin{array}{l}\text { NSABP } \\
\text { B-39 }\end{array}$ & $\begin{array}{l}2005- \\
2013\end{array}$ & 10.2 & 4216 & 54 & IBTR & $\begin{array}{l}\text { IBC or DCIS; } \\
\mathrm{T}<3 \\
\mathrm{~cm}, \leq \mathrm{N} 1 ; \mathrm{R} 0\end{array}$ & $\begin{array}{l}\text { 3DCRT, } \\
\text { single-and } \\
\text { multi- } \\
\text { cath.BT }\end{array}$ & $\begin{array}{l}34 / 3.4 ; \\
38.5 / 3.85 \\
\text { in 5-8d }\end{array}$ & $\begin{array}{l}\text { 50/2; } \\
50.4 / 1.8 \\
\text { opt.Boost }\end{array}$ \\
\hline $\begin{array}{l}\text { Strnad } \\
2016\end{array}$ & GEC Estro & $\begin{array}{l}\text { 04/2004- } \\
07 / 2009\end{array}$ & 6.6 & 1328 & 62 & IBTR & $\begin{array}{l}\text { IBC or DCIS; } \\
\text { T < } 3 \mathrm{~cm} ; \mathrm{RO} ; \\
\text { NO; } \\
>40 \mathrm{y}\end{array}$ & Multicath.BT & $\begin{array}{l}32 / 4 ; \\
30.3 / 4.3 \text { or } \\
\text { PDR }\end{array}$ & $\begin{array}{l}50 / 2 \\
50.4 / 1.8 \\
\text { opt.Boost }\end{array}$ \\
\hline $\begin{array}{l}\text { Veronesi } \\
2013\end{array}$ & ELIOT & $\begin{array}{l}11 / 2000- \\
12 / 2007\end{array}$ & 5.8 & 1305 & $\mathrm{nr}$ & IBTR & $\begin{array}{l}\text { IBC; T<2.5 } \\
\text { cm; R0; 48- } \\
75 y ; \text { unifocal }\end{array}$ & $\begin{array}{l}\text { IORT } \\
\text { electron }\end{array}$ & $21 / 21$ & $50 / 2+$ opt.10/2 \\
\hline $\begin{array}{l}\text { Polgar } \\
2013\end{array}$ & Budapest & $\begin{array}{l}1998- \\
2004\end{array}$ & 10.5 & 258 & $\begin{array}{l}\text { Mean } \\
59\end{array}$ & $\begin{array}{l}\text { local } \\
\text { recurrence }\end{array}$ & $\begin{array}{l}\text { IBC; T<2 } \\
\text { cm; NO; R0; } \\
\text { GI-2; unifocal }\end{array}$ & $\begin{array}{l}\text { Multicath. } \\
\text { BT 3DCRT }\end{array}$ & $\begin{array}{l}\text { BT:36.4/5.2 } \\
\text { BID; } \\
\text { e:50/2 QD }\end{array}$ & $50 / 2+$ opt. $16 / 2$ \\
\hline $\begin{array}{l}\text { Coles } \\
2017\end{array}$ & $\begin{array}{l}\text { Import } \\
\text { low }\end{array}$ & $\begin{array}{l}05 / 2007- \\
10 / 2010\end{array}$ & 6 & 1343 & 62 & IBTR & $\begin{array}{l}\text { IDC; T < } 3 \\
\text { cm; } \\
>50 \text { y; pNO-I }\end{array}$ & 3DCRT & 40/2.67 QD & \\
\hline $\begin{array}{l}\text { Owen } \\
2006\end{array}$ & $\mathrm{RMH} / \mathrm{GOC}$ & $\begin{array}{l}01 / 1986- \\
03 / 1998\end{array}$ & $9 \cdot 7$ & 1410 & 54.5 & IBTR & $\begin{array}{l}\text { IBC; T1-3, N0- } \\
\text { 1, MO }\end{array}$ & & & $50 / 2$ \\
\hline $\begin{array}{l}\text { Whelan } \\
2010\end{array}$ & Canadian & $\begin{array}{l}04 / 1993- \\
09 / 1996\end{array}$ & 12 & 1234 & n.r & IBTR & $\begin{array}{l}\text { IBC; T1-3, N0- } \\
\text { 1, MO }\end{array}$ & & & $50 / 2$ \\
\hline $\begin{array}{l}\text { Spooner } \\
2012\end{array}$ & & $\begin{array}{l}\text { 08/1985- } \\
12 / 1992\end{array}$ & 16.9 & 358 & 59 & $\begin{array}{l}\text { time to first } \\
\text { locoregional } \\
\text { relapse }\end{array}$ & $\begin{array}{l}\text { clinical stage } \\
\text { I and II }\end{array}$ & & & $50 / 2$ \\
\hline $\begin{array}{l}\text { Haviland } \\
2013\end{array}$ & START A & $\begin{array}{l}01 / 1991- \\
12 / 2002\end{array}$ & 12.4 & 2236 & 57 & $\begin{array}{l}\text { LRR, normal } \\
\text { tissue } \\
\text { effects and } \\
\text { quality of life }\end{array}$ & $\begin{array}{l}\text { IBC; T1-3, N0- } \\
\text { 1, MO }\end{array}$ & & & $50 / 2$ \\
\hline $\begin{array}{l}\text { Haviland } \\
2013\end{array}$ & START B & $\begin{array}{l}01 / 1991- \\
12 / 2002\end{array}$ & 12.4 & 2215 & 57.4 & $\begin{array}{l}\text { LRR, normal } \\
\text { tissue } \\
\text { effects and } \\
\text { quality of life }\end{array}$ & $\begin{array}{l}\text { IBC; T1-3, NO- } \\
\text { 1, MO }\end{array}$ & & & $50 / 2$ \\
\hline $\begin{array}{l}\text { Wang } \\
2020\end{array}$ & & $\begin{array}{l}08 / 2010- \\
11 / 2015\end{array}$ & 5 & 729 & 46 & LR & $\begin{array}{l}\text { 18-70y; } \\
\text { T1/2;RO;NO }\end{array}$ & & & $\begin{array}{l}50 / 2+ \\
\text { opt. } \\
10 / 2\end{array}$ \\
\hline $\begin{array}{l}\text { Brunt } \\
2020\end{array}$ & FAST & $\begin{array}{l}10 / 2004 \\
-3 / 2007\end{array}$ & 10 & 915 & $\begin{array}{l}\text { mean } \\
62.9\end{array}$ & $\begin{array}{l}\text { photographic } \\
\text { change in } \\
\text { beast } \\
\text { appearance }\end{array}$ & $\begin{array}{l}\geq 50 \mathrm{y} ; \\
\mathrm{IBC} ; \\
\mathrm{T}<3 \mathrm{~cm} ; \mathrm{RO} ; \mathrm{NO}\end{array}$ & & & $50 / 2$ \\
\hline
\end{tabular}

1. According to The Cochrane Collaboration's Risk of Bias Tool, a total of six bias items were judged by review authors, which are random sequence generation (selection bias), allocation concealment (selection bias), Blinding of participants and personnel (performance bias), Blinding of outcome 
assessment (detection bias), Incomplete outcome data (attrition bias) and Selective reporting (reporting bias). The risk of bias summary for each included study is listed in this column, where $\oplus$ represents low risk of bias, $\boldsymbol{\theta}$ represents high risk of bias, and represents unclear risk of bias.

2. Abbreviations: No:number; n.r.:not reported; PBI: partial breast irradiation; CF-WBI: conventional fractionated whole breast irradiation;HF-WBI: Hypofractionated whole breast irradiation;G3:pathology grade 3; x photons; y years; IDC: Invasive ductal carcinoma; LR: Local recurrence; LRR, localregional relapse; DCIS: Ductal carcinoma in situ; N+: lymph nodules positive; Multicath.BT: multicatheter brachytherapy; HER-2+: HER-2 positive; HT:

Adjuvant therapy with hormone; IBC: Invasive ductal carcinoma; IMRT: Intensity-modulated radiotherapy; CTx: chemotherapy; ET: endocrine therapy; IBTR: ipsilateral breast tumor recurrence; ;ORT: intraoperative radiotherapy; HR+: hormone receptor positive;R0:R0 excision,the surgical margin was negative;NO:No lymph node metastasis;T:T stage of tumor.MO:No distant metastasis.

\section{Figures}
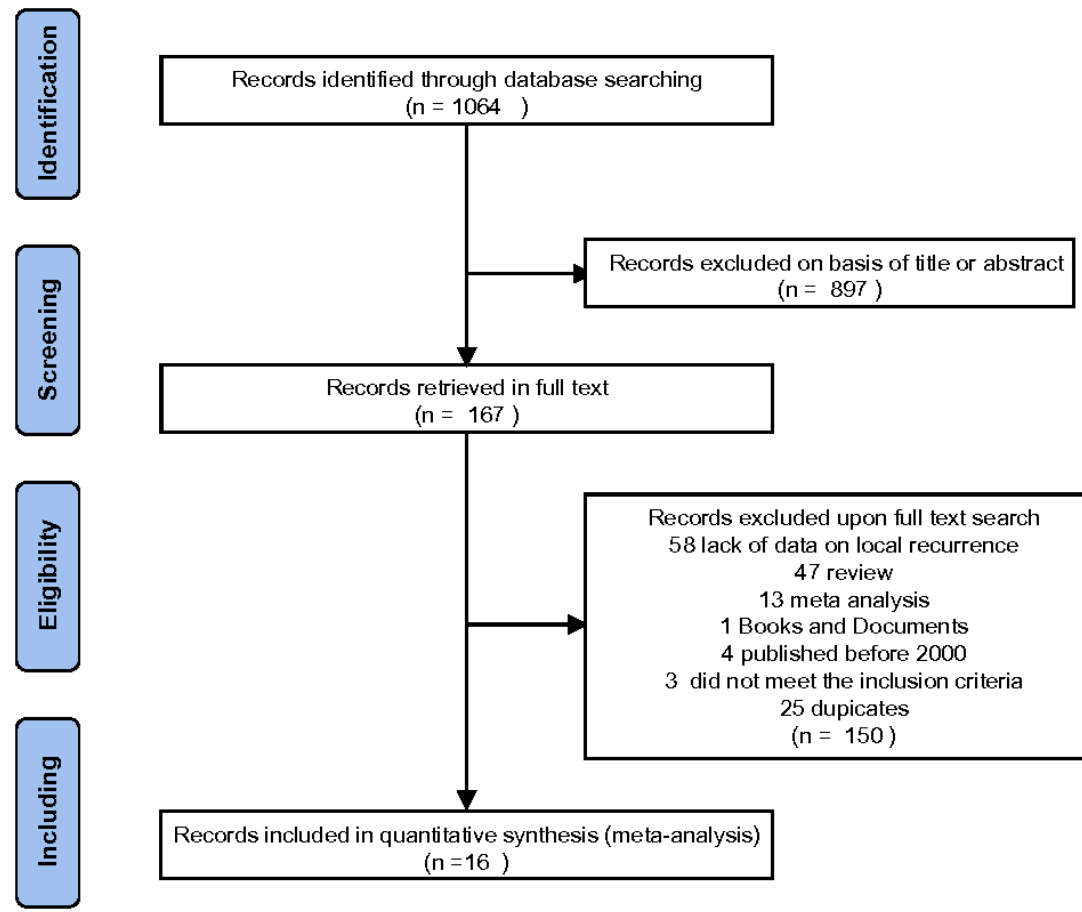

Records excluded upon full text search 58 lack of data on local recurrence 47 review

13 meta analysis

1 Books and Documents

4 published before 2000

3 did not meet the inclusion criteria

25 dupicates

$(n=150)$

Records included in quantitative synthesis (meta-analysis)

$(n=16)$

\section{Figure 1}

Consort diagram showing the results of the literature review according to the PRISMA guidelines. 


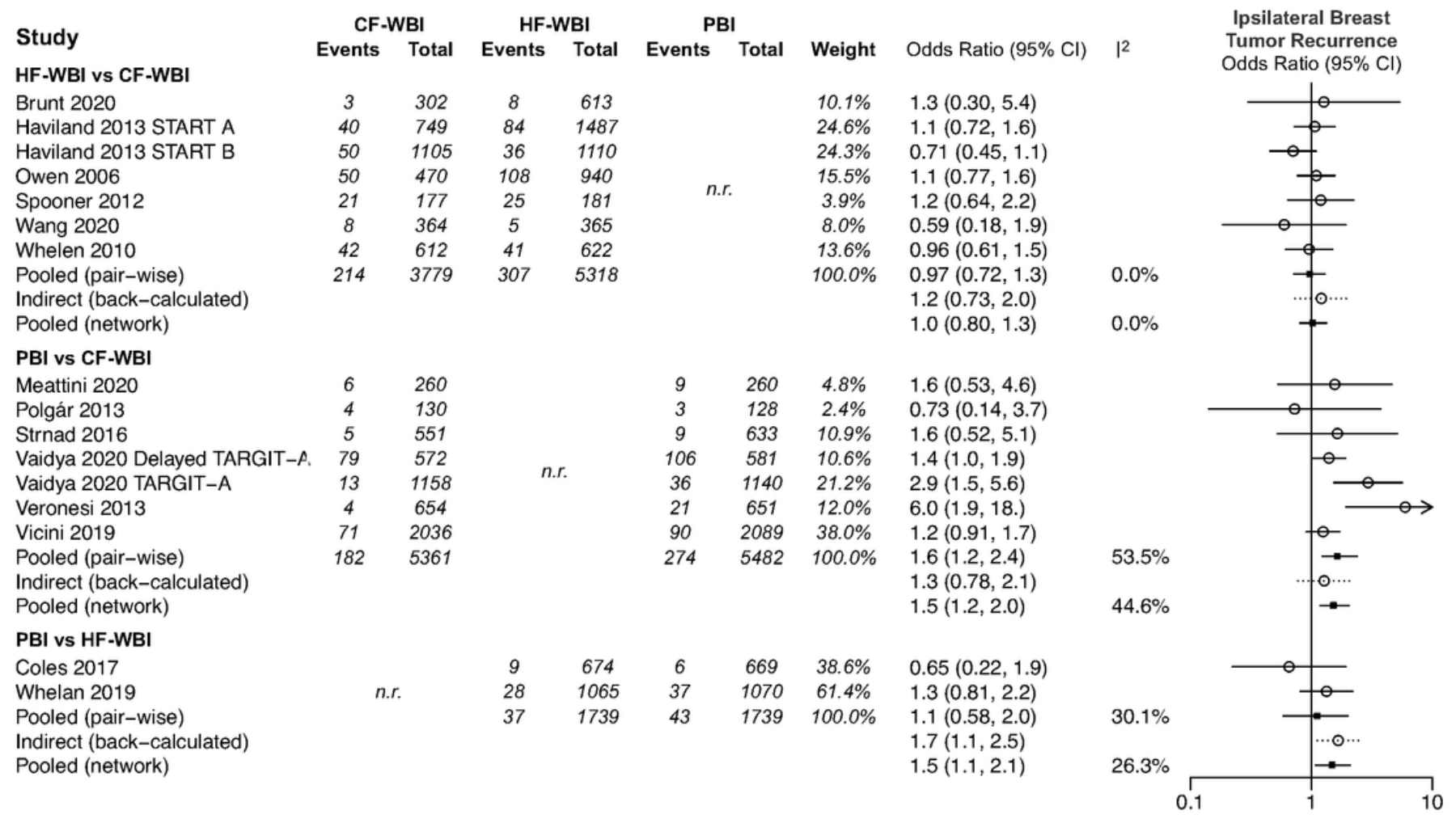

Figure 2

Comparison of IBTR by forest plots with odds ratios using conventional pair-wise meta-analysis and network meta-analysis, and network meta-ranking. Circle and quadrats represent individual trials and pooled effect sizes with corresponding $95 \%$ confidence intervals.

Study
HF-WBI vs CF-WBI
Brunt 2020
Haviland 2013 START A
Haviland 2013 START B
Spooner 2012
Whelen 2002
Pooled (pair-wise)
Indirect (back-calculated)
Pooled (network)
PBI vs CF-WBI
Meattini 2020
Polgár 2013
Strnad 2016
Vaidya 2020 Delayed TARGIT-A
Veronesi 2013
Vicini 2019
Pooled (pair-wise)
Indirect (back-calculated)
Pooled (network)
PBI vs HF-WBI
Coles 2017
Whelan 2019
Pooled (pair-wise)
Indirect (back-calculated)
Pooled (network)

$\begin{array}{lllll}\text { CF-WBI } & \text { HF-WBI } & \text { PBI } & \\ \text { Events Total Events Total Events Total Weight Odds Ratio }(95 \% \mathrm{Cl})\end{array}$

$\begin{array}{cccc}17 & 302 & 30 & 613 \\ 100 & 749 & 231 & 1487 \\ 158 & 1105 & 121 & 1110 \\ 24 & 177 & 29 & 181 \\ 26 & 612 & 48 & 622 \\ 325 & 2945 & 459 & 4013\end{array}$

$\begin{array}{cc}8 & 260 \\ 11 & 130 \\ 5 & 551 \\ 67 & 572 \\ 35 & 654 \\ 49 & 2036 \\ 175 & 4203\end{array}$

260

130
551

572

654

2036

4203

n.r.

$\begin{array}{ccc} & 13 & 674 \\ \text { n.r. } & 18 & 1065 \\ & 31 & 1739\end{array}$

12
20
32

669
1070
1739

$13.2 \%$

$32.1 \%$

n.r.

$31.8 \%$

$5.1 \%$

$17.7 \%$

$100.0 \%$

$0.87(0.47,1.6)$

$1.2(0.93,1.5)$

$0.73(0.57,0.94)$

$1.2(0.67,2.2)$

$1.9(1.2,3.1)$

$1.1(0.79,1.5)$

$1.0(0.58,1.8)$

$1.1(0.81,1.4)$

$\begin{array}{cc} & 7 \\ & 7 \\ \text { n.r. } & 5 \\ & 71 \\ & 33 \\ & 65 \\ & 188\end{array}$

260
128
633
581
651
2089
4342

$6.1 \%$

$3.0 \%$

$13.9 \%$

$13.5 \%$

$15.3 \%$

$48.3 \%$

$0.86(0.30,2.5)$

$0.61(0.22,1.7)$

$0.86(0.24,3.2)$

$1.0(0.73,1.5)$

$0.94(0.58,1.5)$

$1.3(0.89,1.9)$

$1.0(0.70,1.4)$

$1.1(0.60,2.0)$

$1.0(0.76,1.4)$

$0.93(0.41,2.1)$

$1.1(0.58,2.1)$

$1.0(0.54,2.0)$
$0.95(0.61,1.5)$

$0.98(0.66,1.4)$

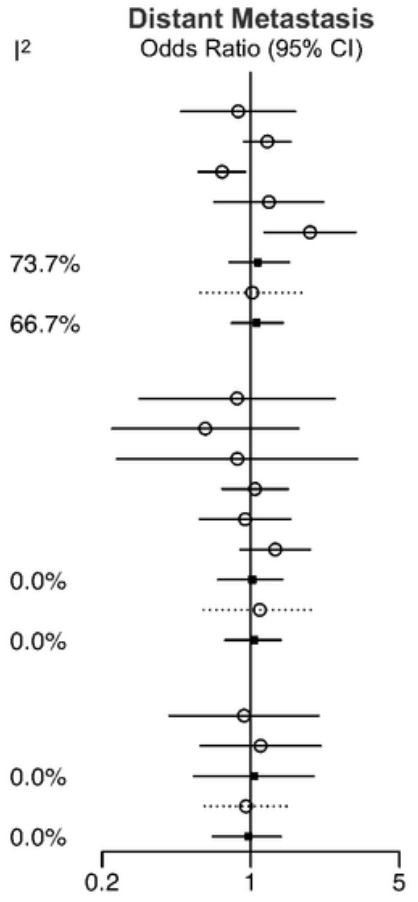

Figure 3 


Study
HF-WBI vs CF-WBI
Brunt 2020
Haviland 2013 START A
Haviland 2013 START B
Spooner 2012
Whelen 2010
Pooled (pair-wise)
Indirect (back-calculated)
Pooled (network)
PBI vs CF-WBI
Meattini 2020
Strnad 2016
Vaidya 2020 Delayed TARGIT-A
Vaidya 2020 TARGIT-A
Veronesi 2013
Vicini 2019
Pooled (pair-wise)
Indirect (back-calculated)
Pooled (network)
PBI vs HF-WBI
Coles 2017
Whelan 2019
Pooled (pair-wise)
Indirect (back-calculated)
Pooled (network)

CF-WBI HF-WBI PBI

Events Total Events Total Events Total Weight Odds Ratio $(95 \% \mathrm{Cl})$

$\begin{array}{cccc}30 & 302 & 66 & 613 \\ 130 & 749 & 262 & 1487 \\ 192 & 1105 & 159 & 1110 \\ 92 & 177 & 98 & 181 \\ 126 & 612 & 122 & 622 \\ 570 & 2945 & 707 & 4013\end{array}$

$\begin{array}{cc}20 & 260 \\ 32 & 551 \\ 59 & 572 \\ 75 & 1158 \\ 31 & 654 \\ 174 & 2036 \\ 391 & 5231\end{array}$

$\begin{array}{lll}18 & 260 & 4.9 \%\end{array}$

$\begin{array}{lll}27 & 633 & 11.2 \%\end{array}$

n.r.

n.r.

$13.2 \%$
$32.1 \%$
$31.8 \%$
$5.1 \%$
$17.7 \%$
$100.0 \%$

n.r.

$\begin{array}{lll}40 & 674 & 37 \\ 27 & 1065 & 25 \\ 67 & 1739 & 62\end{array}$

$\begin{array}{cc}669 & 38.6 \% \\ 1070 & 61.4 \% \\ 1739 & 100.0 \%\end{array}$
$1.1(0.69,1.7)$

$1.0(0.81,1.3)$

$0.79(0.63,1.0)$

$1.1(0.72,1.7)$

$0.94(0.81,1.1)$

$1.1(0.71,1.6)$

$0.96(0.83,1.1)$

$0.89(0.45,1.7)$

$0.72(0.42,1.2)$

$1.1(0.75,1.6)$

$0.91(0.65,1.3)$

$1.1(0.67,1.8)$

$1.1(0.91,1.4)$

$1.0(0.85,1.2)$

$0.90(0.60,1.3)$

$1.0(0.84,1.2)$

$0.93(0.59,1.5)$

$0.92(0.53,1.6)$

$0.93(0.64,1.3)$

$1.1(0.85,1.4)$

$1.0(0.84,1.3)$
$0.94(0.71,1.2)$
Total Death

$\mathrm{I}^{2} \quad$ Odds Ratio $(95 \% \mathrm{Cl})$

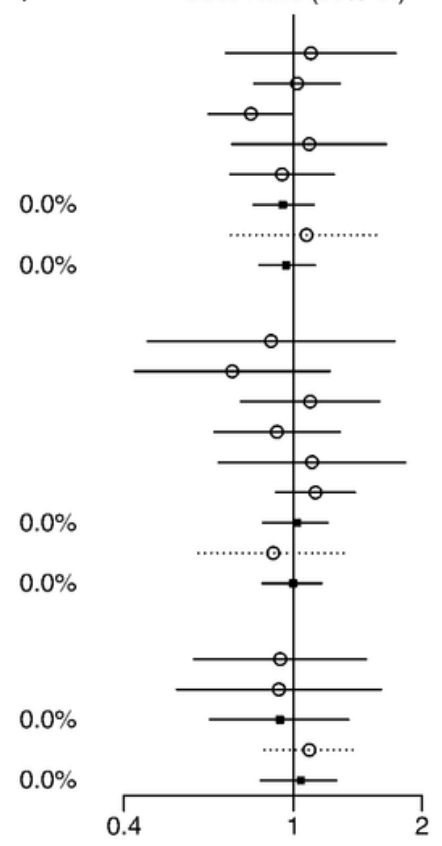

Figure 4

Comparison of total death by forest plots with odds ratios using conventional pair-wise meta-analysis, network meta-analysis, and network meta-ranking. Circles and quadrats represent individual trials and pooled effect sizes with corresponding $95 \%$ confidence intervals.

Study
HF-WBI vs CF-WBI
Brunt 2020
Haviland 2013 START A
Haviland 2013 START B
Whelen 2010
Pooled (pair-wise)
Indirect (back-calculated)
Pooled (network)
PBI vs CF-WBI
Meattini 2020
Polgár 2013
Vaidya 2020 Delayed TARGIT-A
Vaidya 2020 TARGIT-A
Veronesi 2013
Vicini 2019
Pooled (pair-wise)
Indirect (back-calculated)
Pooled (network)
PBI vs HF-WBI
Coles 2017
Pooled (pair-wise)
Indirect (back-calculated)
Pooled (network)

CF-WBI HF-WBI PBI

Events Total Events Total Events Total Weig Odds Ratio $(95 \% \mathrm{Cl}) \quad \mathrm{I}^{2}$

$\begin{array}{cccc}23 & 302 & 48 & 613 \\ 38 & 749 & 81 & 1487 \\ 62 & 1105 & 53 & 1110 \\ 44 & 612 & 40 & 622 \\ 167 & 2768 & 222 & 3832\end{array}$

$\begin{array}{ccl} & 13.9 \% & 1.0(0.62,1.8) \\ & 33.9 \% & 1.1(0.73,1.6) \\ \text { n.r. } & 33.6 \% & 0.84(0.58,1.2) \\ & 18.7 \% & 0.88(0.57,1.4) \\ 100.0 \% & 0.95(0.71,1.3) \\ & & 1.0(0.56,2.0) \\ & & 0.97(0.74,1.3)\end{array}$

$\begin{array}{cc}12 & 260 \\ 10 & 130 \\ 42 & 572 \\ 74 & 1158 \\ 11 & 654 \\ 130 & 2036 \\ 279 & 4810\end{array}$

$\begin{array}{ll}260 & \\ 130 & \\ 572 & \\ 1158 & \text { n.r. } \\ 654 & \\ 2036 & \\ 4810 & \end{array}$

n.r.

$\begin{array}{ll}31 & 674 \\ 31 & 674\end{array}$

$\begin{array}{ccc}13 & 260 & 5.4 \% \\ 10 & 128 & 2.7 \% \\ 44 & 581 & 11.9 \% \\ 45 & 1140 & 23.8 \% \\ 11 & 651 & 13.5 \% \\ 150 & 2089 & 42.7 \% \\ 273 & 4849 & 100.0 \%\end{array}$

$1.1(0.48,2.5)$

$1.0(0.40,2.6)$

$1.0(0.66,1.6)$

$0.60(0.41,0.88)$

$1.0(0.42,2.4)$

$1.1(0.89,1.4)$

$0.95(0.72,1.2)$

$0.87(0.50,1.5)$

$0.93(0.73,1.2)$
$\begin{array}{llll}27 & 669 & 100.0 \% & 0.87(0.51,1.5)\end{array}$
$27 \quad 669 \quad 100.0 \% \quad 0.87(0.45,1.7)$
$0.99(0.67,1.5)$
$0.96(0.68,1.3)$

Non-breast Cancer Death Odds Ratio $(95 \% \mathrm{Cl})$

$0.0 \%$

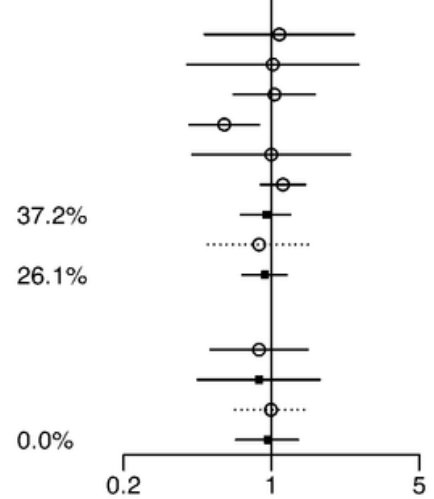


Figure 5

Comparison of non-breast cancer deaths by forest plots with odds ratios using conventional pair-wise meta-analysis, network meta-analysis, and network meta-ranking. Circles and quadrats represent individual trials and pooled effect sizes with corresponding $95 \%$ confidence intervals. 